\title{
Articles
}

\section{Precipitation of Manganese in the $p$-Xylene Oxidation with Oxygen-Enriched Gas in Liquid Phase}

\author{
Sung Hwa Jhung ${ }^{*}$ and Youn-Seok Park \\ Samsung General Chemicals Co., Ltd. San 222-2. Dokgod-Ri, Daesan-lp, Seosan-Si. Chungnam 356-711, Korea \\ Received August 31,2001
}

\begin{abstract}
The liquid phase oxidation of $p$-xylene has been carried out with oxygen-enriched gas, and the manganese component was precipitated probably via over-oxidation to $\mathrm{Mn}^{\text {t+ }}$. The precipitation increased with rising oxygen concentration in the reaction gas and occurred mainly in the later part of the oxidation. The activity of the reaction decreased, and the blackening of the product and side reactions to carbon dioxide increased with the degree of precipitation. Precipitation can be decreased with the addition of metal ions. such as cerium. chromium and iron
\end{abstract}

Keywords : Terephthalic acid. p-Xylene oxidation. Oxygen-enriched gas. Manganese precipitation. Blackening.

\section{Introduction}

Terephthalic acid (TPA) is one of the most important chemicals. with an annual production capacity of nore than 24.000 .000 tons in the year 2000 . Korea's production of TPA, $4,540.000$ tons per year, is the highest in the world. ${ }^{1}$ TPA, the raw material of polyester. is usually produced conumercially by liquid phase oxidation of $p$-xylene $(\mathrm{pX})$ with air using a catalyst combination of cobalt, manganese and bromide ions in acetic acid at around $170-210^{\circ} \mathrm{C}^{.3 .3}$

Considering the huge production capacity of TPA. even small improvements of the process are very important from an economic view. The desired inprovements of the TPA process have been described elsewhere. ${ }^{3}$ and the studies to improve the liquid phase oxidation of alkyl aromatics with catalyst of metal/bromine have been reviewed in detail by Partenheimer. $^{4}$

Detailed studies. such as kinetics ${ }^{5-11}$ and mechanism ${ }^{3.56 .15 .18}$ on the liquid phase oxidation of alkyl aromatics to aromatic carboxylic acids have been carried out. It has also been attempted to replace the acetic acid solvent with water ${ }^{19.30}$ and to eliminate the corrosive bromine component ${ }^{1,22}$ and to utilize carbon dioxide as a co-oxidant ${ }^{t \hat{y}}$ There have been numerous efforts, ${ }^{5,24.25}$ to improve the $\mathrm{Co} / \mathrm{Mn} / \mathrm{Br}$ catalyst system. including the addition of transition and lanthanide metals, such as zirconium, cerium and hafnium.

The oxidation with oxygen-enriched gas has been studied by Praxair technology Inc. ${ }^{36}$ and Mitsui petrochemical industry ${ }^{37}$ to improve the TPA process. Clains were made that the reactor volume could be decreased and the reaction yield was high with the oxygen-enriched gas. A higher efficiency of reaction was obtained by utilizing a special

${ }^{*}$ Corresponding author. Tel: +82-41-660-636l: Fax: +82-41-6606369; e-mail: shihung atsansung.co.kr apparatus called LOR (liquid oxidation reactor), ${ }^{26}$ because of the enhanced efficiency of mixing and the increased contacts between the substrates and the reaction gas. The amount of reactor exhaust gas could be decreased also. ${ }^{27}$ Therefore, the TPA process with oxygen-enriched gas is very promising.

The precipitation of manganese to decrease the cluromaticity of product in $p$-sylene oxidation has been reported when the $\mathrm{Br} /(\mathrm{Mn}+\mathrm{Co})$ ratio of catalyst is low or water concentration is high ${ }^{28}$ The precipitated manganese causes the blackening of the product due to the precipitated black manganese material. ${ }^{-8.29}$ The mechanism of manganese precipitation has been explained as being due to $\mathrm{MnO}_{2}$ formed from the disproportionation of $\mathrm{Mn}^{3+}$, and this precipitation could be prevented or decreased with the addition of cerium component. ${ }^{28}$ The oxidation of $p$-tolualdehyde can be accompanied with the precipitation of manganese and this precipitation can be decreased with additional metal components, such as cerium, lanthanum. chromium. iron, and etc. ${ }^{29}$ Preventing the precipitation of metal components is important because these materials can contaminate the hydrogenation catalyst for PTA (purified TPA) ${ }^{28}$ deteriorate the product and make the recycling of solvent containing catalyst difficult. The preferential precipitation of a component can be even a serious problem because the operation is more difficult due to the recycling of solvent containing catalysts and the difficulty in maintaining the optimum catalyst concentration

Therefore, studying the precipitation of metal component to overcome the negative effects is necessary. Studying the precipitation in the oxidation of $p$-xylene with oxygenenriched gas is important because of the potential applicability of the process. However, no studies have been made dealing with the precipitation (not only precipitation in the oxidation with oxygen-enriched gas but also precipitation in 
oxidation with high water concentration or low $\mathrm{Br}$ condition) as far as the authors know.

In the present study. the precipitation of manganese, when the oxidation is carried out with oxygen-enriched gas, is reported for the first time. The decrease in activity due to the precipitation is also reported. A method to decrease precipitation and blackening is also suggested.

\section{Experimental Section}

Apparatus. The apparatus for the oxidation reaction is explained elsewhere. ${ }^{3 i j}$ The reaction rate and cunulated conversion were monitored continuously by the consumption rate of oxygen.

Procedure. The procedure for the oxidation reaction is explained elsewhere ${ }^{31 j} 200 \mathrm{~g}$ of reactants $(15 \% p$-xylene. $7.5 \%$ water and $77.5 \%$ acetic acid) were charged in the titanium reactor. The expected oxygen consumption was 848 mniol based on the stoichiometry of p-xylene oxidation only. Based on the total weight of reaction mixture, the catalyst comprised $150 \mathrm{ppm}$ of cobalt, $300 \mathrm{ppm}$ of manganese and $240 \mathrm{ppm}$ of bromine as a base condition. The concentration of each catalyst component was changed to 100.200 and $300 \mathrm{ppm}$ of cobalt. manganese. and bromine. respectively. to study the precipitation in the high $\mathrm{Br} /(\mathrm{Co}+\mathrm{Mn})$ ratio.

An additional metal ion, such as $\mathrm{Ce}^{3+}, \mathrm{Cr}^{\hat{\gamma}^{+}}$or $\mathrm{Fe}^{3-}$ with a weight concentration same as the cobalt $(150$ or $100 \mathrm{ppm}, 50$ ppm for some cases). was added to study the precipitation. The effects of additional cobalt or manganese were also studied with $150 \mathrm{ppm}$ of additional ions.

The oxygen concentration in the gas phase of the reactor was between 50 and $64 \%$. and the nitrogen concentration was changed accordingly.

Reagent. Cobalt acetate tetrahydrate, manganese acetate tetrahydrate and hydrogen bromide were used to prepare the catalyst solution. Cerium(III) acetate. chromium(II) acetate hydrate dimer and iron(II) acetate were utilized as sources of additional metals. All other chemicals. including $p$-xylene and acetic acid. were guaranteed reagent grade.

Analysis. The detailed analysis methods for solid and liquid products are reported elsewhere. ${ }^{30}$ The concentration of metal ions in liquid was determined with ICP and the precipitated material was analyzed with SEM and XPS.

\section{Results and Discussion}

Effects of oxygen concentration and cerium on the

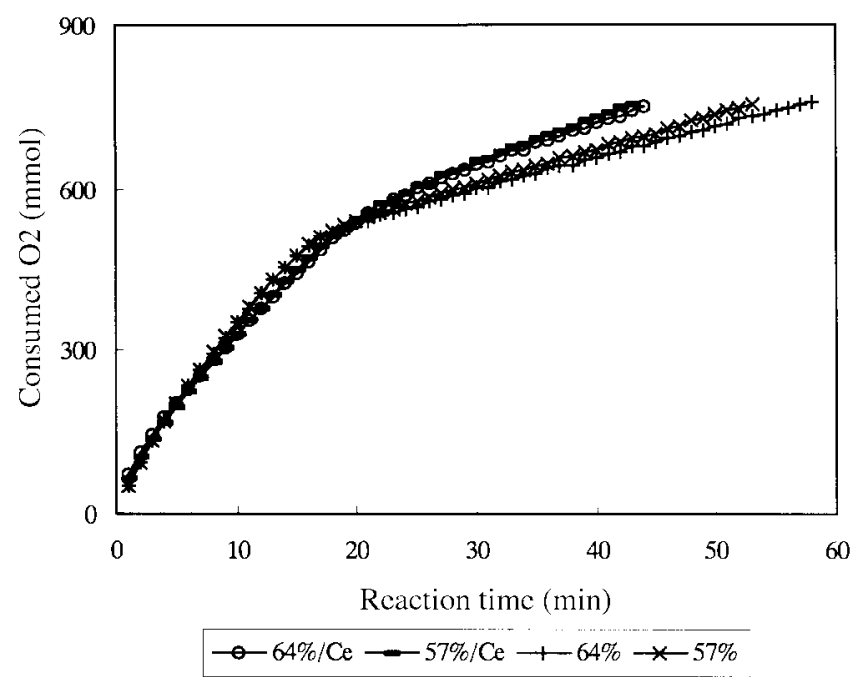

Figure 1. Effect of oxygen concentration and additional cerium on the rate of $p$-sylene oxidation.

oxidation of $p$-xylene. Typical TPA produced from the oxidation of $p$-xylene (the oxygen conversion was $753 \mathrm{mmol}$ or $88.8 \%$ ) with a catalyst of $\mathrm{Co} / \mathrm{Mn} / \mathrm{Br}$, utilizing a gas containing 57 and $64 \%$ oxygen was gray in color for the lower oxygen concentration and dark gray for the higher concentration. The gray particles in TPA did not dissolve in alkaline solution and could be separated as black particles from TPA after dissolution of the TPA in KOH solution. Therefore, the precipitation of a black material on TPA is called blackening. ${ }^{3 y}$ However, the products with the catalyst system of $\mathrm{Co} / \mathrm{Mn} / \mathrm{Ce} / \mathrm{Br}$ showed the typical white color of TPA. Without the additional cerium ion, the oxidation in the later part of the reaction decreased quite sharply (Figure 1). Therefore, the reaction time needed for the oxygen conversion of $88.8 \%$ was ligh for the case of the reaction with the catalyst of $\mathrm{Co} / \mathrm{Mn} / \mathrm{Br}$. The manganese ion retained in solvent was quite low for the case of oxidation with $\mathrm{Co} / \mathrm{Mn} / \mathrm{Br}$ compared with the case of oxidation with $\mathrm{Co} / \mathrm{Mn} / \mathrm{Br} / \mathrm{Ce}$. as displayed in Table 1 and Figure 2. Compared with cobalt, manganese ion precipitated more in solid when the oxygen concentration in the reaction gas was high. Moreover, the precipitation of manganese increased with the concentration of oxygen in the reaction gas. However. the precipitation of manganese did not depend much on the oxygen concentration if the cerium ion was added as a catalyst component.

In summary. the precipitation can be prevented with the addition of cerium in the catalyst system. and the precipi-

Table 1. Effects of oxygen concentration and additional cerium on the $p$-xylene oxidation

\begin{tabular}{ccccccc}
\hline $\begin{array}{c}\mathrm{O}_{2} \text { Concentration } \\
(\%)\end{array}$ & $\begin{array}{c}\text { Additive } \\
\text { metal }\end{array}$ & $\begin{array}{c}\text { Concentration } \\
(\mathrm{ppm})\end{array}$ & $\begin{array}{c}\text { Reaction time } \\
(\mathrm{min})\end{array}$ & $\begin{array}{c}\text { Manganese retention ratio } \\
\text { in mother liquid (\%) }\end{array}$ & $\begin{array}{c}\text { Cobalt retention ratio } \\
\text { in mother liquid (\%) }\end{array}$ & $\begin{array}{c}\text { Color of solid } \\
\text { product }\end{array}$ \\
\hline 64 & - & 0 & 56.6 & 32.6 & 76.5 & Dark gray \\
& $\mathrm{Ce}$ & 50 & 44.2 & 79.4 & 82.2 & White \\
57 & - & 0 & 52.8 & 54.7 & 80.4 & Gray \\
& $\mathrm{Ce}$ & 50 & 42.6 & 81.1 & 85.5 & White \\
\hline
\end{tabular}

Reaction time needed for the consunption of ongen of $753 \mathrm{mmol}$ ( $88.8^{\circ} .00 \mathrm{yg}$ en conversion) 


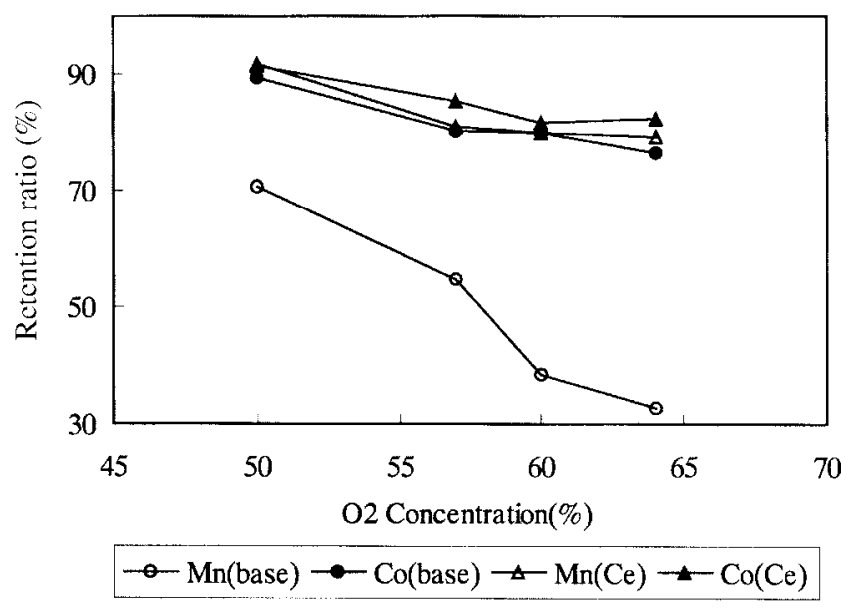

Figure 2. The degree of retention of cobalt and manganese ions in liquid after the oxidation of $p$-xylene with various oxygen concentration and additional cerium. The oxygen conversions of the reaction were $88.8 \%$ and $94.3 \%$ for the case of oxygen concentration of 57 or $64 \%$ and 50 or $60 \%$, respectively.

tation increases with the oxygen concentration of reaction gas.

Effects of additional metals on precipitation. Oxidation reactions with the gas containing $60 \%$ oxygen were carried out with a few additional transition or lanthanide metals. and the oxidation rates are shown in Figure 3. Cobalt or manganese ions (150 ppm each) were added to check the effects on oxidation. The reaction rate was very low in the later part of the reaction with the additional manganese. The added cobalt was not very effective in raising the activity in the later part of the reaction, even though cobalt is one of the most active catalysts for oxidation. Table 2 shows the reaction time needed for the oxygen conversion of $94.3 \%$ ( $800 \mathrm{~mm}$ mol). TPA yield and purity, carbon dioxide concentration in the gas phase. color of solid product, retention ratio of cobalt and manganese and the activity after $30 \mathrm{~min}$. Analyzing the color of the product. we found that the effect to prevent the blackening of TPA with the additional metal is in the order of $\mathrm{Ce} \sim \mathrm{Cr} \sim \mathrm{Fe}>$ base $>\mathrm{Co}>\mathrm{Mn}$. The $p$ sylene oxidation with oxygen-enriched gas was understood to cause the blackening of the product and this can be prevented with the addition of cerium, iron or chromium.
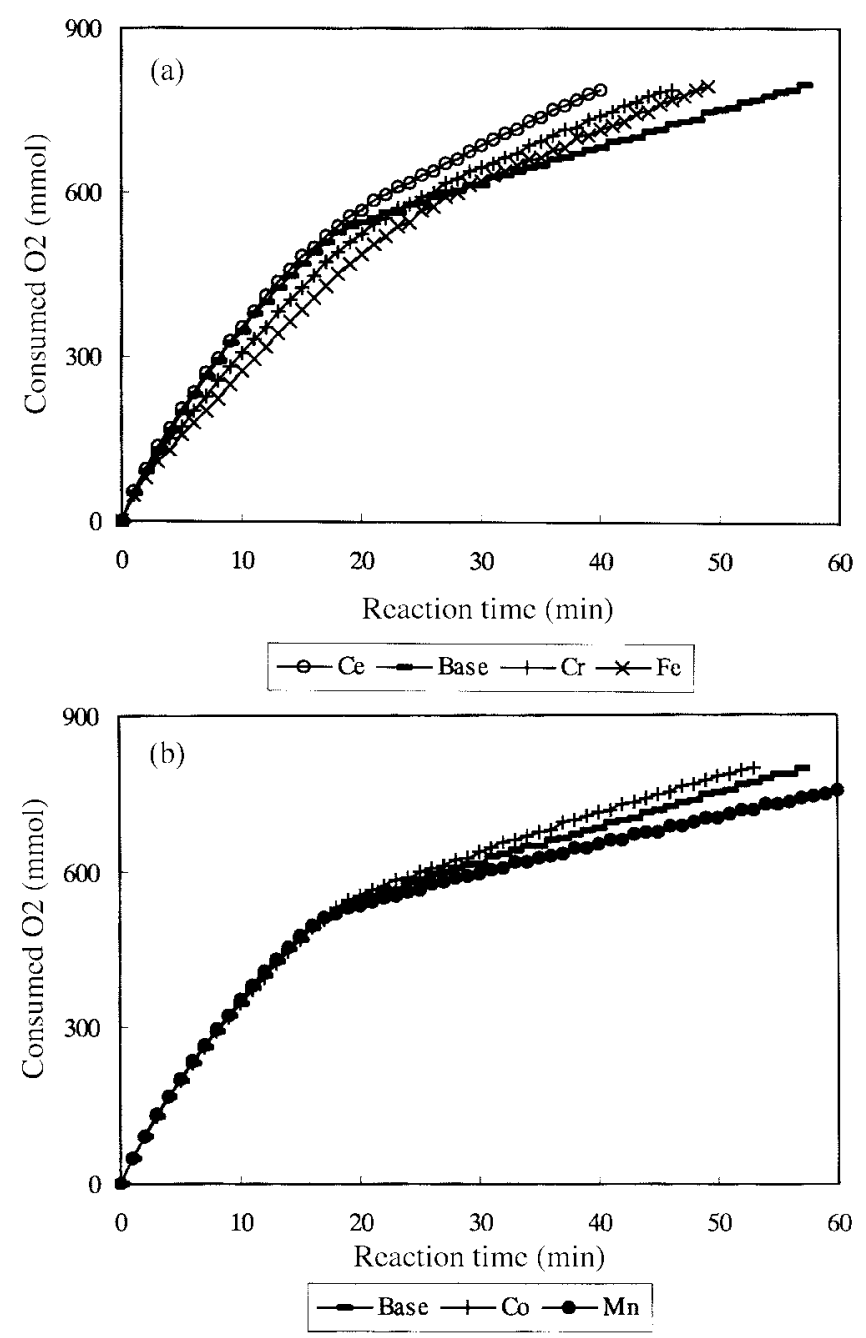

Figure 3. Effect of additional metal ions on the rate of $p$-xylene oxidation. (a) For the case of preventing the blackening except for the base catalyst system. (b) For the case of occurrence of the blackening.

The activity to reach the oxygen conversion of $94.3 \%$ is in the order of $\mathrm{Ce}>\mathrm{Cr}>\mathrm{Fe}>\mathrm{Co}>$ base $>>\mathrm{Mn}$. The rates of oxygen consumption after $30 \mathrm{~min}$ showed a linear dependence on reaction time. Reaction activity (the amount of oxygen consumption per reaction time) after $30 \mathrm{~min}$ was in

Table 2. Effects of additional metal ions on the $p$-xylene oxidation

\begin{tabular}{|c|c|c|c|c|c|c|c|c|}
\hline $\begin{array}{l}\text { Additional } \\
\text { component and } \\
\text { concentration } \\
\text { (ppm) }\end{array}$ & $\begin{array}{l}\text { Reaction Time } \\
\qquad(\mathrm{min})^{*}\end{array}$ & $\begin{array}{c}\text { TPA yield } \\
\text { (wt.\%) }\end{array}$ & $\begin{array}{c}\text { Purity of solid } \\
\text { TPA (wt. } \% \text { ) }\end{array}$ & $\begin{array}{l}\text { Conc of } \mathrm{CO}_{2} \text { in } \\
\text { gas phase after } \\
\text { reaction (vol.\%) }\end{array}$ & $\begin{array}{c}\text { Color of solid } \\
\text { product }\end{array}$ & $\begin{array}{c}\text { manganese } \\
\text { retention ratio } \\
\text { in mother liquid } \\
(\%)\end{array}$ & $\begin{array}{l}\text { cobalt retention } \\
\text { ratio in mother } \\
\text { liquid }(\%)\end{array}$ & $\begin{array}{l}\text { Activity after } \\
30 \mathrm{~min}^{--} \\
\text {(mmol/min) }\end{array}$ \\
\hline- & 57.5 & 74.2 & 92.6 & 20.6 & Dark gray & 38.5 & 80.0 & 6.58 \\
\hline $\mathrm{Ce} 150$ & 41.0 & 75.8 & 92.9 & 18.1 & White & 79.9 & 81.8 & 10.36 \\
\hline $\mathrm{Ct} 150$ & 469 & 75.2 & 92.8 & 19.6 & White & 780 & 82.4 & 9.05 \\
\hline $\mathrm{Fe} 150$ & 49.6 & 73.8 & 92.0 & 20.3 & White & 75.6 & 81.9 & 9.16 \\
\hline $\operatorname{Mn} 150^{\circ}$ & 600 & 65.3 & 88.6 & 19.5 & Black & 13.7 & 73.4 & 5.23 \\
\hline $\operatorname{Cot} 150$ & 53.4 & 74.9 & 92.7 & 21.2 & Very dark gray & 28.7 & 65.3 & 7.05 \\
\hline
\end{tabular}

"Reaction time needed for the consumption of oxygen of $800.0 \mathrm{mmol}\left(94.3^{\circ} \mathrm{o}\right.$ oxygen confersion) except for the case of manganese. ${ }^{\text {*4 }} 753.3 \mathrm{mmol}$ of oxven was consumed for 60 min. ${ }^{-*}$ Refer to the text. Slope of the anount of consumed oxygen with reaction time after 30 min. 
Table 3. Effects of additional ceriun on the $p$-xylene oxidation with the catalyst system of high $\mathrm{Br} /(\mathrm{Co}+\mathrm{Mn})$ ratio. The concentrations of $\mathrm{Co}$, $\mathrm{Mn}$ and $\mathrm{Br}$ were 100,200 and $300 \mathrm{ppm}$, respectively

\begin{tabular}{ccccccc}
\hline $\begin{array}{c}\text { O. Concentration } \\
(\%)\end{array}$ & $\begin{array}{c}\text { Additive } \\
\text { metal }\end{array}$ & $\begin{array}{c}\text { Concentration } \\
(\mathrm{ppm})\end{array}$ & $\begin{array}{c}\text { Reaction } \\
\text { Time(min) }\end{array}$ & $\begin{array}{c}\text { manganese retention ratio cobalt retention ratio in } \\
\text { in mother liquid (\%) }\end{array}$ & $\begin{array}{c}\text { Color of solid } \\
\text { mother liquid (\%) }\end{array}$ & $\begin{array}{c}\text { product } \\
\text { (m) }\end{array}$ \\
\hline 60 & - & 0 & 84.0 & 68.3 & 81.7 & Very bright gray \\
& $\mathrm{Ce}$ & 100 & 84.0 & 83.4 & 82.9 & White \\
\hline
\end{tabular}

Reaction time needed for the consumption of oxygen of $800.0 \mathrm{mmol}$

the order of $\mathrm{Ce}>\mathrm{Fe}>\mathrm{Cr}>\mathrm{Co}>$ base $>\mathrm{Mn}$. The addition of cerium, iron or chromium increased the reactivity in the later part of the reaction. decreasing the reaction time for fixed oxygen conversion, even though chronium and iron decreased the activity as the reaction began. We found that the $16.5 \mathrm{ppm}$ of iron. chromium or nickel decreased the rates of $p$-xylene oxidation by $1-2 \%{ }^{31}$ The rate of oxidation of $p$ toluic acid, through a study to find the effects of corroded reactor materials on the oxidation, was decreased by about $10 \%$ with the addition of $1400 \mathrm{ppm}$ of iron. $400 \mathrm{ppm}$ of chromium or $200 \mathrm{ppm}$ of nickel. ${ }^{\hat{3}}$

The retention ratio of manganese in mother liquid with the additional metal was in the order of $\mathrm{Ce}>\mathrm{Cr}>\mathrm{Fe}>>$ base $>$ $\mathrm{Co} \gg \mathrm{Mn}$. This corresponds quite well with the order to prevent the blackening of the product and the activity of the catalyst system. This may show that the blackening and activity of the reaction are related with the precipitation of manganese. The precipitation of cobalt does not depend much on the additional metals. The precipitation of cobalt was increased a bit with the additional cobalt or nianganese.

The characteristics and effects of precipitation or blackening. The shape and composition of the precipitated black species were analyzed with SEM-EDS and XPS after filtration. SEM-EDS showed a species about 0.5 micron in size and conposed mainly of manganese. The $2 \mathrm{P}_{3}$ and $2 \mathrm{P}_{1: 2}$ peaks of the separated black species (the TPA is removed after dissolution in $\mathrm{KOH}$ solution) have the binding energy of 642.0 and $653.6 \mathrm{eV}$, and were practically similar to the data obtained from $\mathrm{MnO}_{2}\left(2 \mathrm{P}_{3: 2}: 642.1 \mathrm{eV}\right.$. and $2 \mathrm{P}_{1: 2}: 653.8$ $\mathrm{eV}$ ). The binding energy of manganese increased with the oxidation state, as can be easily anticipated. For example. the binding energy $\left(2 \mathrm{P}_{3}\right)$ of $\mathrm{MnO} . \mathrm{Mn}_{3} \mathrm{O}_{3}$ and $\mathrm{MnO}_{2}$ is reported to be about less than 641.4 . about 641.4 and $6+2.0$ $\mathrm{eV}$, respectively. ${ }^{32}$ Therefore. the precipitated black material may be considered a manganese species with an oxidation state of +4 (presumably $\mathrm{MnO}_{2}$ similar to the reference $\mathrm{e}^{28}$ ). However, checking the phase with XRD was impossible because the amount of the material was so snall.

The blackening material has been explained to be $\mathrm{MnO}_{2}$ formed from the disproportionation of $\mathrm{Mn}^{3-}: \mathrm{Mn}^{3-} \rightarrow \mathrm{Mn}^{2+}$ $\left.+\mathrm{Mn}^{4+}\left(\mathrm{MnO}_{2}(\downarrow)\right)\right)^{\text {: }}$ The degree of precipitation of manganese is high when the $\mathrm{Br} /(\mathrm{Co}+\mathrm{Mn})$ ratio is low and water concentration is high. ${ }^{29}$ The blackening due to the precipitation of manganese in the oxidation of $p$-tolualdehy'de is also reported to be high when the concentration of manganese or water is high. ${ }^{28}$

The low precipitation of manganese in the condition of high $\mathrm{Br} /(\mathrm{Co}+\mathrm{Mn})$ ratio has been confirmed in this study. The

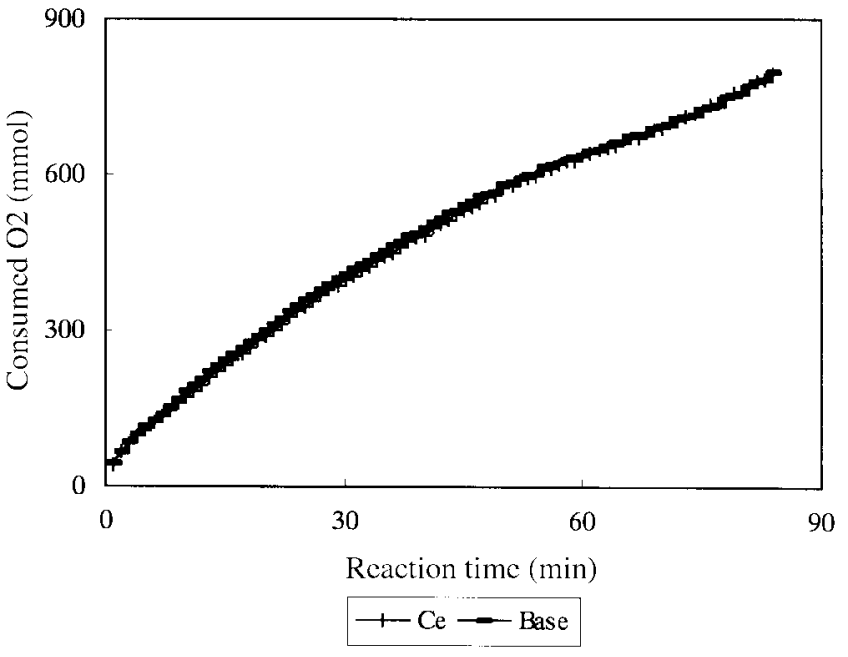

Figure 4. Effect of additional cerium ion on the rate of p-xylene oxidation with the catalyst system of high $\mathrm{Br} /(\mathrm{Co}+\mathrm{Mn})$ ratio. The concentration of $\mathrm{Co}, \mathrm{Mr}$ and $\mathrm{Br}$ was 100, 200 and $300 \mathrm{ppm}$, respectively.

color of TPA produced with the catalyst of Co 100. Mn 200 and $\mathrm{Br} 300 \mathrm{ppm}$ was very bright gray compared with dark gray TPA produced with the catalyst of $\mathrm{Co} 150, \mathrm{Mn} 300$ and $\mathrm{Br} 240 \mathrm{ppm}$. However. the color of the TPA produced with the catalyst with additional cerium (Co 100 . Mn 200, Ce 100 and $\mathrm{Br} 300 \mathrm{ppm}$ ) was the typical white. The retention ratio of manganese in liquid was very high in oxidation with a catalyst of high $\mathrm{Br} /(\mathrm{Co}+\mathrm{Mn})$ ratio (Table 3). The oxygen consumption rate did not depend much on the presence of additional cerium when $\mathrm{Br} /(\mathrm{Co}+\mathrm{Mn})$ ratio was high (Figure 4). This may show that the decrease in activity is related with the precipitation of manganese.

The side reactions to carbon dioxide were checked with the concentration of carbon dioxide. by-products of the oxidation. in gas phase because the amount of side reactions is very important from an economic view. The relative amount of carbon dioxide formation with the additional metal was in the order of $\mathrm{Co}>$ base $>\mathrm{Fe}>\mathrm{Cr}>\mathrm{Ce}$. The amount of the carbon dioxide formed via oxidation with the additional manganese was very high, considering the low oxygen conversion of $88.8 \%$ and low TPA yield. Therefore. we contend that the side reactions to carbon dioxide increase with the degree of precipitation of manganese. This may be related with the fact that the optimum $\mathrm{Co} / \mathrm{Mn}$ ratio cannot be maintained from precipitation of manganese because cobalt is well known to have very high activity to the formation of carbon dioxide and carbon monoxide. ${ }^{15}$ 
The blackening due to the oxidation with enriched oxygen is reported here for the first time. We suggest that the precipitated manganese may be the reason for decreased activity, especially in the later part of the reaction.

An explanation for the precipitation or blackening. The precipitation or blackening occurs more readily when the bromine concentration is low or water concentration is high ${ }^{25.29}$ Considering the well known mechanism ${ }^{3.5}$ of the oxidation, it may be supposed that the precipitation of manganese occurs when the rate of redox cycle between the bromine and a substrate is slow due to the high concentration of water (water is well known to retard the reaction ${ }^{5}$ ) or decreased free radical carrier, bromine radical. In other words. if the concentration of substrate that can be easily oxidized is relatively low, the precipitation may occur through the oxidation of manganese to $\mathrm{Mn}^{4+}$. The oxidation of manganese to $\mathrm{Mn}^{4-}$ and the oxidation of substrates may be competing processes because the blackening was not observed even in the oxidation using $\mathrm{Co} / \mathrm{Mn} / \mathrm{Br}$ catalyst with low $\mathrm{Br} /(\mathrm{Co}+\mathrm{Mn})$ ratio when the oxygen conversion was less than about $60 \%$.

The precipitation of manganese may be explained by the over-oxidation from $\mathrm{Mn}^{3-}$ or $\mathrm{Mn}^{3-}$ to $\mathrm{Mn}^{4-}$ rather than from the disproportionation of $\mathrm{Mn}^{3-}$ to $\mathrm{Mn}^{3+}$ and $\mathrm{Mn}^{4-}$ as suggested in the reference $e^{\text {ts }}$ if it can be agreed that the precipitation occurs only when the oxygen concentration is high and occurs mainly in the later part of the reaction. The manganese component may exist as soluble $\mathrm{Mni}^{\hat{2}^{-}}$or $\mathrm{Mn}^{3+}$ and interchange via the well known redox $\mathrm{cycle}^{3,5}$ in the beginning of the reaction (when there remains sufficient substrate to be oxidized). The nanganese can be over-oxidized with oxygenenriched gas only when the reaction rate is low due to the increased water concentration or low concentration of free radical carrier.

Therefore. the cerium. chronium or iron may increase the activity of the substrates, such as $p$-xylene, $p$-toluic acid or 4-carboxybenzaldehyde, in the later part of the reaction via a subtle interaction with the catalyst of $\mathrm{Co} / \mathrm{Mn} / \mathrm{Br}$ and decrease the precipitation of manganese. A fundamental study with EPR and UV-VIS etc. is necessary to clarify the precipitation or blackening in the oxidation of alkyl aromatics.

\section{Conclusions}

In the liquid phase oxidation of $p$-xylene with oxygenenriched gas the manganese component can be precipitated probably via over-oxidation to $\mathrm{Mn}^{4^{-}}$. The precipitation seems to increase with oxygen concentration in reaction gas and occur mainly in the later part of oxidation. The oxidation activity decreases and the blackening and side reactions to carbon dioxide increase with the degree of precipitation.
Precipitation can be decreased with the addition of metal ions such as cerium, cluromium or iron.

Acknowledgment. The authors thank Mr. K. H. Lee and Dr. Jin S. Yoo for their excellent advice.

\section{References}

1. http : www hyosungehemical.comenglish

2. http i www utmledudepartments artsci chemistry Terephthalic Acid.html

3. Chavan. S. A.; Halligudi. S. B.: Srinivas, D; Rantnasamy P. $d$. 110l. Catal A 2000, 161,49.

4. Terephthalic Acid. Chem Systems: 1999: Vol 9798-5.

5. Partenheimer. W. Catal. Todav 1995. 23.69.

6. Sheldon. R. A.: Kochi. I. K. Metal-Catahzed Oxidations of Organic Compomins: Academic Press: New York, 1981: Ch. 5 and Ch. 10 .

7. Cincotti, A.: Orru. R.: Cao. G. Catal Todav 1999. 52.331

8. Cincotti. A.: Oru. R.: Broi. A.: Cao. G. Chent. Eng. Sci. 1997. 52. 4205.

9. Igarashi. T.: Lusztyk. T.: Ingold. K. U. J. Am. Chem. Soc. 1992. $11+7719$.

10. Igarashi, J.; Jensen, R. K.: Lusztyk. J.; Korcek, S ; Ingold, K. U. J. Am. Chem. Soc. 1992, 114,7727.

11. Rofía. P.: Calina. P.: Tonti. S. Oxidation Comm 1985/1986. 8 . 167.

12. Dugmore. G. M.: Powels. G. T.: Zeelie. B. J. Mol Catal. A 1995. 99. 1.

13. Partenheimer. W. In Catalysis of Organic Reactions' Kosak. J. R.. Johnson. T. A., Eds, Mareel Dekker: New York. 1994; 188.

14. Partenheimer. W.: Kaduk. T. A. Stud Sinf. Sci. Catal. 1991. 66. 613.

15. Partenheimer. W. In Catahysis of Organic Reactions. Blackburn. D. W. Ed.: Marcel Dekiker: New York. 1990: 1321.

16. Akhtar, S.: Zaidi, H. Appl Catal 1986. 27.99.

17. Hanotier. J Hanotier-Bridoux. M. J. Mol. Catal. 1981, 12. 133

18. Okada. T.: Kamiya. Y. Bull. Chem. Soc. Jpn. 1979.52.3321.

19. Harustiak. M.: Honnec. M.: Ilavshy. T. J. Mol. Catal. 1989. 53. 209.

20. Hronec. M.; Ilavshy. J. React. Kinet. Catal. Lett. 1987, $33,323$.

21. Jacob. B. R.: Varkey. S. P.: Ratnasamy: P. Appl. Catal A 1999. 182.91.

22. US Pat. 5760288 (1998). to Mitsubishi chemical corp.

23. Yoo. I. S.: Thung. S. H.: Lee. K. H.: Park. Y.-S. Appl Catal. A 2002. 223. 239.

24. Gipe. R. K; Partenheimer. W. Stud. Surf. Sci. Catal. 1997, 110. 117.

25. Chester. A. W.: Scott. E. J. Y.: Landis. P. S. J. Catal. 1977, 46. 308.

26. US patent 5696285 (1997). to Praxair Technology Inc.

27. US patent 5596129 (1997). to Mitsui petrochem. Ind.

28. US patent 5453538 (1995), to Amoco corp.

29. US patent 4211882 (1980), to Mitsubishi gas chem. Co.

30. Jhung. S. H.: Lee. K. H.: Park. Y.-S. Bull Korean Chem. Soc. 2002. 23. 59 .

31. Thung. S. H.: Park. Y.-S. unpublished results.

32. Wagner. C. D.: Riggs. W. M.: Davis. L. E.: Moulder. J. F.: Muilenberg. G. E. Handbook of liray Photolectron Spectroscopy: Perkin-Elmer Corp.: Eden Prairie, 1979: pp 74-75. 